\title{
The Study of Design Semiotics and Architectural Space Semantics
}

\author{
Pu-Hua YAN \\ Key Laboratory of Disaster Forecast and Control in Engineering, Ministry of Education of China; \\ College of Science and Engineering, Jinan University, Guangzhou 510632, P. R. China \\ tyanpuhua@jnu.edu.cn
}

Keywords: Design Semiotics, Architecture, Space, Semantics.

\begin{abstract}
This paper summarizes the main theory and development status of semiotics in the field of architectural design. Using the basic principles of design semiotics, it analyzes the context of space capabilities in the field of architectural design, space syntax building mode, and the aesthetic and spiritual space vocabulary expressed functional space. The import of semiotics in architectural design field provides people a new research path to explore architectural design methods, research space frame model, and understand architectural significance.
\end{abstract}

\section{Development and Research Value of Design Semiotics in the Field of Architectural Design}

Design semiotics in the field of architectural design has been widely used. Hegel had proposed "the building is a symbolic symbol with building materials". [1]German modernist architect Walter Gropius said: "Architecture is the crystallization of the performance of people lofty ideas, passion, humanity, faith, and religion". [2] That shows the architectural space as a plastic art, it contains profound emotional symbol. The architectural historian Nikolaus Pevsner in his "A History of Building Types" wrote: "Modern architecture and architectural significance can not be separated, it conveys to people simple, sophisticated and new technologies means and so on". [3] C - Jenks in the book "Signs, Symbols and Architecture" point out that architectural symbols reveal the significance of architectural, by the association of signifer and signified. The Japanese architect and theorist Kisho Kurokawa, pointed out that: "Talking about postmodern architecture, we should talk about semiotics which is more sophisticated research on the contemporary world, in modern architecture and traditional issues". [4]

\section{Design Semiotics and Architecture}

\section{"Signifier" and "Signified" of Architecture}

Signifier and signified, which is the center of Saussure theory. In the symbol system, he thinks that the presence of the symbol depends on the combination of the signifier and the signified. If we regard a building as a symbol, then the form of the works is a signifier, the information and meaning it passed is signified.

Tab.1 Symbol signifier and signified

\begin{tabular}{ccc}
\hline symbol & signifier & signified \\
\hline Common symbols & Symbols form & Meaning of symbols \\
\hline Architecture symbols & $\begin{array}{c}\text { Space, wall interface,furniture, colors, } \\
\text { materials, lighting, etc. }\end{array}$ & $\begin{array}{c}\text { Function, emotional, } \\
\text { culture, status, etc. }\end{array}$ \\
\hline
\end{tabular}

\section{Classification of Architectural Design Symbols}

According to Pierce symbols classification, symbols can be divided into the following three categories: image symbol of architecture, indicative symbol of architecture, and symbolic symbol of architecture. 
Image symbol of architecture means that symbol image is similar to building image. Indicative symbol of architecture means that there is a causal or spatial logic connection between symbols and architecture. Symbolic symbol of architecture means that there is no direct link between the symbol and the building, but by convention to produce a certain conception of the association.
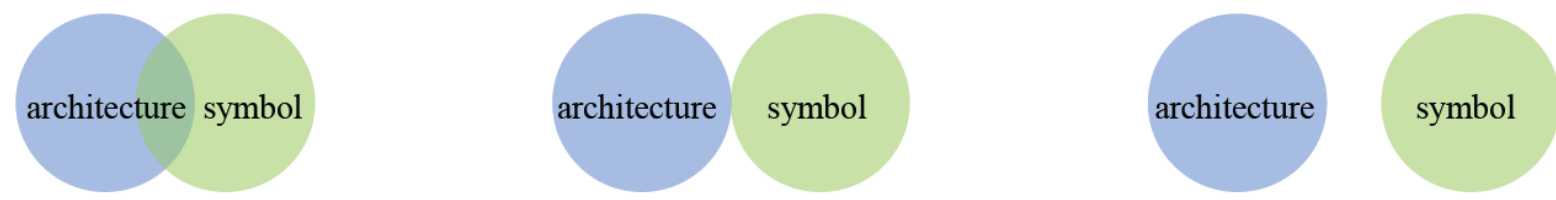

Image symbol of architecture Indicative symbol of architecture Symbolic symbol of architecture

Fig. 1 Classification of architectural design symbols

\section{Coordinates of Architectural Design Symbol}

Regarding the composition of symbols, Saussure has proposed an important symbol system concept: Paradigms and Syntagms, which both constitute the coordinates of the architectural symbols. Vertical relationship: the pedigree polymerization of symbols in different architectural space, such as space-style context, spatial recognition, etc, that is paradigms. Transverse relationship: structural combination of different symbols in the same building space, such as form, space, color, texture, lighting, etc, that is syntagms.

\section{Architectural Symbols Spread}

In the process of architectural design symbols spreading, the building itself can not speaking, but they have verbal communication characteristics and the resulting significance, classical or modern, sacred or intimate, ecological or simple, etc.

\section{Design Semiotics and Building Space Semantics}

\section{Paradigms of Architectural Design Symbols - Space Context}

Building space context is a set of spatial vocabulary according to spatial grammar, and consisting of a model with consistency, repeatability and identification.

\section{Syntagms of Architectural Design Symbols - Space Vocabulary}

\section{Vocabulary of Architectural Forms}

Point, line, and surface constitute the basic elements of art and design in the form of two-dimensional symbols. Space body is the basic element of the three-dimensional forms of architectural symbols. Space body is the important carrier of architectural design symbol information, and a symbol of visual communication. The elements of point, line, surface, and body are one of the basic vocabularies between architect and user information transfer. Design symbol value lies not in its physical form or structure itself, but its semantics shown by external form.

Gestalt psychology points out that the brain will be simplified, in order to understand the specific visual environment. We know from the geometry, the basic shape is circular and the regular polygon which inscribed in the circle. In these forms, the most important is the following basic shapes: circle, triangle and square.

Round as architectural vocabulary, it is a centralized and introversion shape. Typically, the semantics of its expression is stable and self-centered. Put a circle in the center of a place, it will enhance its internal concentric. Put a circular form with a straight or angled together, it can cause a significant rotation movement. [5].

The semantics of the triangle is stable. When the triangle is situated in one of its edge, it tells a very stable pattern. However, the triangle with one vertex to be the support, it describes the unstable equilibrium state, or in an unstable state, tilting to one side. 


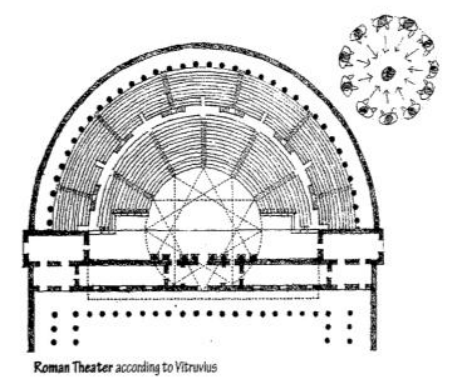

Source: Architecture: Form, Space and Order

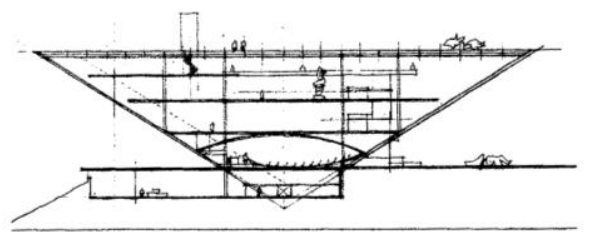

Fig. 2 Form, Space and Order

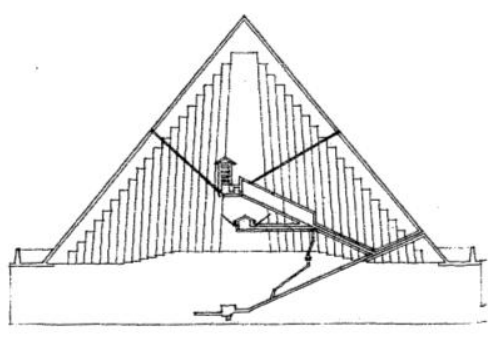

The semantics of square is pure and rational. When the square is situated in one of its edge, it is stable. The square in an angle as a support, it is dynamic. The diagonal to the vertical or horizontal, the square is in static equilibrium.

\section{Vocabulary of Architectural Space}

\section{Space Vocabulary of Horizontal Elements}

Elevation space means that the space is compelling, important. Sunken space gives us a hidden, protected and peaceful feeling.

The top surface and the ground define a region of space. The top surface of the space can become an active visual vocabulary, or make the space has directionality.

\section{Space Vocabulary of Vertical Elements}

A vertical line, such as a pillar, an obelisk or a tower, it established a point on the ground, attracting our attention.

Vertical height affects the degree of shelter space. When the vertical height is two feet, it is hardly to provide a sense of enclosure. When it is waist-high, vertical plane begins to produce a sense of enclosure, while maintaining visual continuity with the surrounding space. When it approaches our eye level, the space is divided into two spaces. When it exceeds our height, it is completely interrupted the continuity between the two areas of visual and spatial, and providing a strong sense of enclosure space.

L-shaped vertical expresses inward in the inner corners and outward at its outer edge. For a group of parallel vertical, its spatial semantics is extroversion because of its parallel surface does not intersect. For U-shaped vertical, in its closed end, the scope is well defined, and in the open end of the U-shaped, field becomes extroversion. Four vertical enclosed spaces have the strongest privacy.

\section{Traffic Vocabulary}

Construction of traffic vocabulary formations affects our perception of architecture form and space. It contains the entrance of the building, the shape of the path, and the relationships of path and spatial, etc.

\section{Vocabulary of Architectural Color}

Color symbol is the most sensitive elements of the visual perception of space, with " expressing emotion" function. It gives rise to physical and psychological reactions. This "silent language" guides us to design and control the color of the architectural space to a certain extent.

\section{Vocabulary of Architectural Material}

The material of architectural design semiotics perspective does not refer to the physical attributes and technical characteristics of the material, but the impression it has created. For example, a flat smooth marble can give us a clean sophisticated feelings, texture clear wood gives a natural warm feelings, mirror stainless express precision and high-tech. 


\section{Vocabulary of Architectural Lighting}

Le Corbusier in his "vers une architecture "remarked that architecture is massing in the sun, doing clever, appropriate and excellent performances. Our eyes are born to observe the form of light; light and shadow show the shape of the building. The color, intensity, size, and angle of the building's light and shadow make the space extremely rich light effects.

\section{Summary}

The introducing of design semiotics in the field of architecture provides a new path for researching the theory of building space and space frame mode. It help us to recognize the building on a new level, understand the meaning of the building, especially on the "reading" and evaluation of postmodernism, providing a new way.

\section{References}

[1]Hegel's aesthetics, Vol.3. Beijing : Commercial Press.(1981),p.16.

[2]Peter B. Jones. Function and Character, Architectural Review, (1980).

[3]N. Pevsner. A History of Building Types, Thames and Hudson, London.(1976).

[4]Fuhe Zhang: Visit the famous architect Kisho Kurokawa . World Architecture 8306. (75).

[5]Francis D. K .Ching. architecture : form, space and order. Tianjin: Tianjin University Press .(2005),p.39. 